\title{
EMPHASIZING TEXT STRUCTURE STRATEGY INSTRUCTION TO SCAFFOLD 11TH GRADE STUDENTS' READING COMPREHENSION
}

\author{
${ }^{\mathbf{1}}$ Ni Made Andreiya Eliata \& ${ }^{\mathbf{1}}$ Fauzi Miftakh \\ ${ }^{1}$ English Language Department, Universitas Singaperbangsa Karawang, Indonesia \\ Corresponding Author Email: madeandreiya@gmail.com
}

\section{Article Info \\ Article History \\ Received: August 2021 \\ Revised: September 2021 \\ Published: October 2021}

Keywords

Reading Comprehension;

Reading Instruction;

Text Structure Strategy;

\begin{abstract}
Reading and comprehending an English informational text always becomes a burdensome activity for Indonesian students. This problem arises because of students' low English language competency and insufficient application of traditional reading instruction that teachers teach in regular school. Therefore, this present study has the aim to investigate the implementation of Text Structure Strategy as reading instruction to scaffold students' informational text reading. Due to the COVID-19 outbreak, the learning process of text structure instruction in this study was conducted in the online learning situation. Researchers employed a qualitative case study design with observation as a data collection technique. This study involved 33 participants of 11th-grade students in a class in SMA Negeri 1 Cibitung, West Java, Indonesia. Based on Braun and Clarke's thematic analysis, the result describes that Text Structure Strategy instruction can scaffold learners informational text reading in two main activities, namely introducing the concept of Text Structure Strategy and teaching explicit instruction activity, precisely in modeling and guiding practice.
\end{abstract}

How to cite: Eliata, N. M. A., \& Miftakh, F. (2021). Emphasizing Text Structure Strategy Instruction to Scaffold $11^{\text {th }}$-Grade Students' Reading Comprehension, JOLLT Journal of Languages and Language Teaching, 9(4) pp. 411-421. DOI: https://doi.org/10.33394/jollt.v\%vi\%i.3998

\section{INTRODUCTION}

Reading is one of the most staple and crucial capabilities that EFL learners should have since it can assist them in many fields in real life, not only on an educational level but also on their life afterward. However, abundant EFL learners still face some difficulties to read and comprehending English text. Researchers have witnessed these reading comprehension problems mainly emerge in a non-fiction or informational text reading (Denton et al., 2015; Tortorelli, 2019). Informational texts have unfamiliar topics and forms, commonly use specific terms and some linguistic features that are different from the narrative text (Tortorelli, 2019). Denton, Enos, and York (2015) state that unfamiliar characteristics of informational texts can affect students' engagement when reading and comprehending the text. Therefore, informational texts such as argumentative and expository may decrease learners' interest in reading due to their limited vocabulary and relevant schemata. Thus learners often face some difficulties in comprehending and decoding meaning from informational texts (Denton et al., 2015).

Furthermore, the lack of learners' reading comprehension also relies on the reading instruction that teachers teach. Unfortunately, EFL teachers in regular schools, especially in Indonesia, often draw little attention in teaching reading comprehension to learners. Teachers do not try to teach learners how to read and comprehend the text by themselves, but instead, teachers prefer to teach traditional reading, such as paying attention to vocabulary and answering questions after reading the text (Ghorbani Shemshadsara et al., 2019). Moreover, Williams (2018) states that teachers also focus more on responding and reading the text aloud to their students. Besides making reading activity uninteresting, this conventional reading 
instruction certainly does not let learners to have in-depth interaction with the text and give them an opportunity to gain various reading strategies that can assist them in comprehending the text.

Therefore, learners can gain various strategies from reading instructions that teachers have implemented in the classroom. Empirical studies have proven that instruction in comprehension strategies is effective in assisting learners in learning reading comprehension (Grabe \& Stoller, 2020; Williams, 2005). According to Cervetti and Hiebert (2020), appropriate reading instruction may lead learners to be successful readers since it can develop six vital components: students' knowledge, vocabulary, fluency, phonics, and phoneme awareness and comprehension. Thus, it is important for the teacher to teach appropriate reading instruction that can give learners various reading strategies that they can re-apply when comprehending assigned-reading task independently.

For several years, empirical studies have suggested teachers implement various reading instructions that can scaffold learners to comprehend an English text, and one of them is the text structure strategy (Andre, 1987; Fisher \& Frey, 2015; Grabe \& Stoller, 2020). Text structure strategy will teach students to acknowledge the generic structure that writers use in the text. The text basically consists of a set of coherent rhetorical structure that forms a meaning. Besides representing the connection among the ideas, writers used text structure to organize their ideas, so they could convey some information which is the main purpose of the writing. Text Structure Strategy (TSS) will teach learners to identify the main structural component (e.g., text structure, paragraph structure, signaling words) in a text and remember a set of generic questions that signal those main components (Williams, 2005). Moreover, Wijekumar, Meyer, and Lei (2020) inform that in-text structure strategy, learners will be learned to choose main ideas in a text and then create logical connections between those ideas and adjust them with their background knowledge. In addition, text structure strategy is a reading strategy that teaches learners to figure out and associate the important ideas in a text by seeing some text organization, pattern, and features, then integrating those ideas with their existing schemata to grasp the text meaning.

Acquainting learners to the hierarchical structure may reduce difficulties when comprehending informational text because learners will be more focused on exploring important aspects such as content and structure of the text instead of doing a boring activity such as finding the meaning of unfamiliar words (Ghorbani Shemshadsara et al., 2019). Moreover, learners do not always require reading informational text from beginning to end, but they can apply a reading strategy that can help them find the important fact or information which they need to know (Harner, 2014) hence. By using the text structure strategy, learners will learn to focus on the main information in several paragraphs which can be a foundation to achieve the purpose of the text (Roehling et al., 2017). Teaching informational text structure to learners may simplify learners to recognize the most important points in a text and give effect to their ability to encode and recall the text meaning.

Practical studies have investigated the process of teaching text structure strategy instruction mostly focusing on recognizing text structural components, such as signal words, paragraph structure, summarization, and text visualization (Bogaerds-Hazenberg et al., 2020). This instruction may direct learners' attention and knowledge to the "fish-bone" structure of the informational text and help them to construct the same structural pattern of the text on their cognition. Furthermore, text structure strategy instruction is also known as explicit instruction, which provides needed support for learners through think-aloud or modeling practice, assisted practice, corrective feedback, and purposeful, independent practice (Hughes et al., 2017; Zimmermann \& Reed, 2020). Likewise, Bogaerds-Hazenberg, Evers-Vermeul, and Van den Bergh (2020) conveyed the process of Text Structure Strategy Instruction also refers as responsibility model, which the first two activities are depended on teachers (giving 
direct instruction, modeling), and the rest two activities are more students-focused (guided practice, independent practice). On students-focused activities, teacher will continually lessen comprehension scaffolding and let students take a lead from group practice, pair-practice, and individual practice. Besides, can train students comprehension skill, this activity can also give opportunity for students to become independent and active learners.

Text Structure Strategy has been proven as effective instruction to scaffolds as well as develops reading comprehension for students in various educational levels. Although, text structure strategy is used majorly as an effective strategy to scaffold struggling reader with learning disabilities (e.g., dyslexia) for comprehending and recalling information from the informational text (Bogaerds-Hazenberg et al., 2020; Strong, 2020; Zimmermann \& Reed, 2020), the utilization of text structure strategy also can be seen in formal educational, such in primary and middle-grade level (Ray \& Meyer, 2011; Wijekumar et al., 2018; Williams, 2005, 2018). Meanwhile, in the EFL context, the utilization of Text Structure Strategy for informational text mostly occurred at the university level (Aghasafari, P.; Malayeri, 2015; Ghorbani Shemshadsara et al., 2019; Rohman, 2017; Wu \& Alrabah, 2020).

However, the implication of Text Structure Strategy on EFL secondary high school level in online learning situation especially at Indonesia has rarely been studied directly. Besides that, there is also little empirical study that explores the implementation of this instruction in online learning situations. Addressing this issue, this qualitative case study will focus to explore the implementation of text structure strategy in online learning situations to scaffold 11th-grade students' at SMAN 1 Cibitung reading comprehension precisely in reading informational text.

\section{RESEARCH METHOD}

\section{Research Design}

This current study used a qualitative case study design. Creswell (2013) declares that a case study is a research design that investigates a single case (bounded system) or multiple cases (multiple bounded systems) in the period of time through explicit and rigorous data collection, and then report the finding in description and case-based theme. Therefore, researchers used a case study because this study wants to focus on a single case: the implementation of Text Structure Strategy (TSS) instruction in online learning situations to scaffold learners' informational text reading.

\section{Subjects of the study}

The subjects in this study were 11th-grade students from IPA 3 class on SMA Negeri 1 Cibitung, West Java, Indonesia. This class consists of 33 students, which divide into ten male and 23 female students. Researchers chose this class because researchers had observed the teaching and learning process in this class before. Moreover, this class was also the place where students' comprehension problems had emerged.

\section{Data Collection Techniques}

Researchers analyzed the data collected from group observation. All data were collected through an online situation due to the COVID-19 pandemic outbreak. Researchers conducted online observation through Google Meeting to look closely at students' interaction and behavior when learning this TSS strategy. The observation data had been collected through documentation (e.g., video recorder), observation checklist, and field notes. However, during this online observation, the researcher positioned herself as a participant outsider and a participant insider (Creswell, 2013). As a participant outsider, the researcher only observed the teaching and learning process in the classroom without giving an intervention. Meanwhile, as a participant insider, the researcher would move to the setting and teach an intervention of Text Structure Strategy to participants. 


\section{Data Analysis Technique}

The collected data were analyzed by using Braun and Clarke's (2006) thematic analysis. The analysis process took four main stages. First, researchers organized all the raw data that had already been gotten from observation. After that, researchers transcribed the data from the observation checklist, field notes, and documentation (video recorder). Researchers will then read the transcription carefully. The reduction process also happened in the first stages. Since researchers use various sources of observation data, it is necessary to reduce some unimportant data, so the data will be more relevant and easier to code. In the next second stage, researchers coded all the transcription data. Researchers highlighted some sentences or phrases in transcription that were fascinating and relevant to the research question. Those highlights would be turned into several codes or brief descriptions. The third stage is identifying the codes into some similar patterns or themes. Moreover, researchers used a deductive approach when identifying the themes. These deductive themes are based on existing theoretical data in the literature review regarding the practice of text structure strategy. Finally, in the last step, researchers described each theme and interpreted their overall relationship with the research purpose. In this last process, researchers would also give the final result and conclusion of the study.

\section{RESEARCH FINDINGS AND DISCUSSION Research Findings}

The process of teaching Text Structure Strategy instruction was conducted for three meetings. All meetings were conducted in an online learning situation which used the Google Classroom application as the main learning media. At the beginning of the study, the teacher asked students to activate their web camera, but unfortunately, only a few students who activated their web camera. Furthermore, in the teaching and learning process, the teacher decided to use both the Indonesian language and the English language. The Indonesian language was used to explain and deliver the material. Meanwhile, the English language was used to read the definition and ask students some guided questions that related to the text.

Therefore, based on thematic data analysis from observation data, it was found that text structure strategy may scaffold learners in reading and comprehending informational text in two main activities. Those two activities are (1) introducing the basic concept of Text Structure Strategy and (2) teaching explicit instruction of Text Structure Strategy.

Table 1.

List of themes and codes from observation data

\begin{tabular}{|c|c|c|}
\hline Main Codes & Sub-themes & Themes \\
\hline $\begin{array}{l}\text { Asking students' about their understanding about text } \\
\text { structure }\end{array}$ & \multirow{2}{*}{$\begin{array}{l}\text { Activating students' } \\
\text { background } \\
\text { knowledge }\end{array}$} & \multirow{7}{*}{$\begin{array}{l}\text { Introducing the concept of } \\
\text { Text Structure Strategy } \\
\text { instruction }\end{array}$} \\
\hline $\begin{array}{l}\text { Asking students' to mention various kinds of English } \\
\text { text }\end{array}$ & & \\
\hline Teaching about structure in a text & \multirow{5}{*}{$\begin{array}{l}\text { Teaching direct } \\
\text { instruction of text } \\
\text { structure strategy }\end{array}$} & \\
\hline $\begin{array}{l}\text { Teaching definition, function, and how to use Text } \\
\text { Structure Strategy }\end{array}$ & & \\
\hline Teaching about 5 informational text structures & & \\
\hline Teaching about paragraph structure & & \\
\hline Teaching about signal words & & \\
\hline Teacher demonstrated to identify signal words in the text & \multirow{4}{*}{ Modeling practice } & \multirow{4}{*}{$\begin{array}{l}\text { Teaching explicit instruction } \\
\text { of Text Structure Strategy }\end{array}$} \\
\hline $\begin{array}{l}\text { Teacher demonstrated to analyze paragraph structure in } \\
\text { the text }\end{array}$ & & \\
\hline Teacher empowered students to analyze topic sentence & & \\
\hline $\begin{array}{l}\text { Teacher asked students some simple comprehension } \\
\text { question that related with the text examples }\end{array}$ & & \\
\hline
\end{tabular}




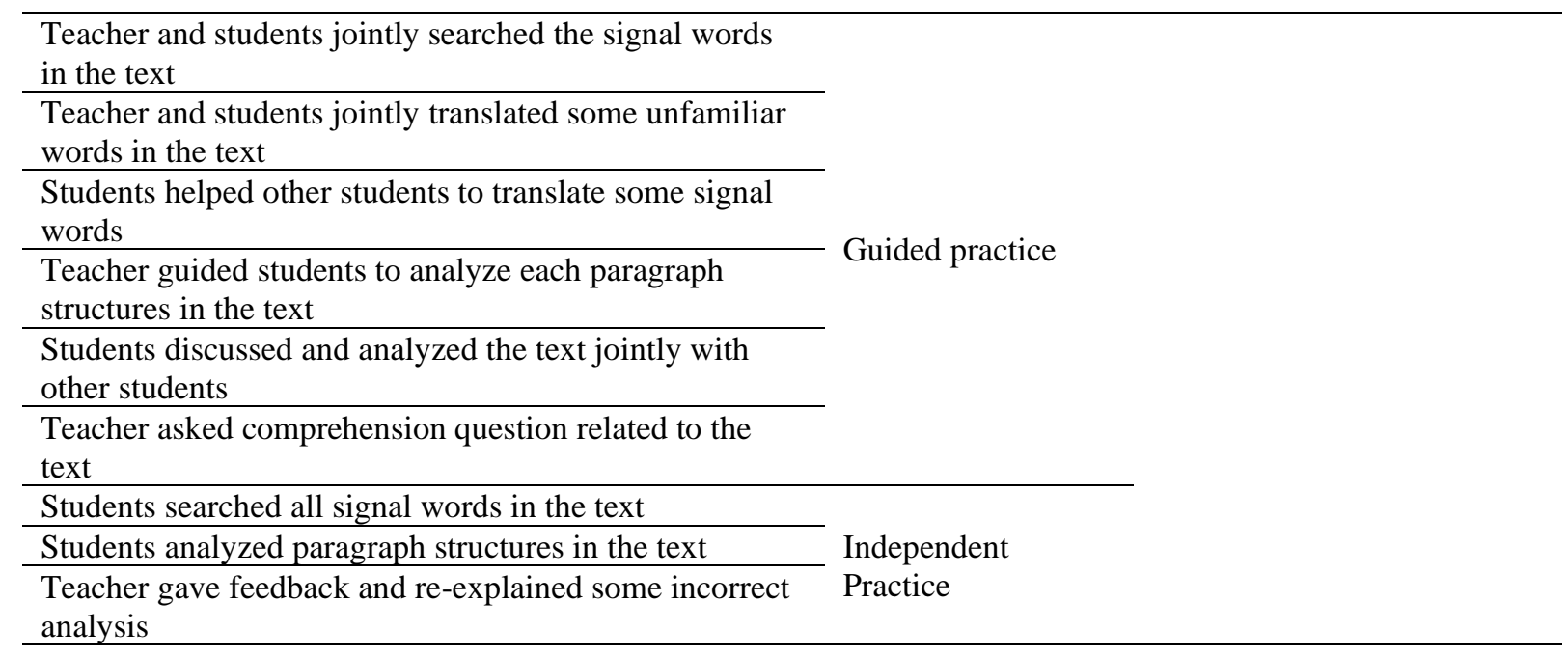

\section{Discussion}

\section{Introducing the basic concept of Text Structure Strategy}

Since text structure strategy is a brand-new concept for students, it was really necessary to introduce students to basic concepts of this strategy. The introduction activity was held on the first meeting. The basic concept of Text Structure Strategy that the teacher taught in this current study mainly focus on conventional components in the text as conveyed by BogaerdsHazenberg, Evers-Vermeul, and Van den Berg (2020). Furthermore, the teaching of conventional components of text structure strategy is also known as direct instruction. In this instruction, students will learn about five informational text structures, paragraph structure, as well as transition signals that the writer used in a text. Learners will be trained to sort out some main ideas in a text through perceiving and focusing on a set of discourse signaling systems (e.g., signal words), create logical associations between those ideas, and incorporate them with background knowledge in this direct instruction (Ghorbani Shemshadsara et al., 2019; Wijekumar et al., 2020).

Introducing text structure strategy to students began with presenting PowerPoint Presentation about the concept of text structure. The teacher told students about the importance of structure in a text for the writer to assemble their ideas. By knowing the importance of text structure for writers, students could understand the relation of each important idea in the text to convey a meaning, as well as to create the same mental structures of the text in their schemata, so they could successfully comprehend the text (Grabe \& Stoller, 2020). Moreover, the teacher also gave an example of how the writer uses text structure.

Afterward, the teacher began to give the overview of text structure strategy instruction as Zimmerman and Reed's (2020) practical theory recommended. In this activity, teacher explained about definition of text structure strategy and its function to help readers find writer's main idea, summarize long text, and understand the text. The teacher also explained the differences between text structure strategy instruction and other traditional reading instruction that students have ever learned before. The teacher also gave students a brief explanation of how to use this Text Structure Strategy to analyze the text. This finding is also in line with Hughes, Morris, and Therrien's (2017) study regarding text structure instruction. Teachers are required to provide a clear explanation of current material, the importance of current material for students, relating students' past experiences with current learning, as well as explaining what students will achieve after learning the material, so they can be academically successful (Hughes et al., 2017).

After giving the overview of Text Structure Strategy, teacher began introduced students with informational text structures and its characteristics. Teacher also explained about the differences between informational and narrative English text. Afterwards, teacher continued 
the lesson by introducing students to five structures of informational text that have been implied by Meyer and Ray (2011), which are description, sequential, comparison, problem and solution, and causation. Furthermore, the teacher explained the structural pattern of each structure that often appeared in informational texts in the form of short paragraphs.

The next activity is teaching paragraph structure. Students were introduced to three parts of paragraph structure, which are topic sentence, supporting sentence, and concluding sentence. The teacher explained to students that paragraph structure could help them to focus more on the main idea of every paragraph in a text. The last activity is teaching about signal words. The teacher explained the function of signal words for showing the connection between ideas in a text and making readers aware of what kind of structure that writers used. Furthermore, the teacher showed and explained some examples of signal words that commonly appear in each informational text structure.

All of those activities were used to inject students' cognition toward the simple explanation of text structure before move to explicit instruction. It is also in line with previous research from $\mathrm{Wu}$ and Alrabah (2020) that claimed introduction activity could help students to approximate the concept of Text Structure strategy. In addition, through this activity, teacher need to make sure that students are aware of the lesson's purpose, as well as can create a connection between current text structure instruction and previous reading strategy that they had learned before (Zimmermann \& Reed, 2020).

Besides introducing students to basic concept of TSS instruction, the teacher also activated students' schemata through this activity. Students' schemata play a pivotal role in reading comprehension since they use their current thinking to relate them with the selected text they face. The finding on observation data is directly agreed with previous studies (Hughes et al., 2017; Roehling et al., 2017) that suggest introducing activity can be an effective way to activate students' schemata before moving to explicit instruction. At the beginning of the lesson, the teacher observed that students had no idea and had never heard about text structure strategy, five informational text structures, paragraph structure, and signal words. However, as the teacher's explanation proceeded, students realized that they had known a little about some concepts. Among five informational text structures, students showed a lot of understanding about description structure because they had learned it before in middle school. On the other hand, sequential structure sounded quite unfamiliar for them, but after looking at the example, they realized that sequential structure is similar to procedure text. They also thought that signal words are similar with the conjunction in a text. This situation shows that students' schemata were successfully activated, and they could relate it with the current lesson, so they can easily understand the concept. Existing background knowledge may influence students' necessities to assist themselves in using text structure (Ray \& Meyer, 2011) which can affect their reading comprehension.

\section{Teaching Explicit Instruction of Text Structure Strategy}

Explicit instruction is of the essence in scaffolding learners when comprehending an Informational text. Explicit instruction consists of several activities, such as modeling activity, guided practice, and independent practice. Explicit instruction also led students to recognize in-depth how structural elements in text are related to each other in constructing writer's ideas. Thus, this explicit instruction may have positive effects on students' reading comprehension and recall (Aghasafari, P.; Malayeri, 2015).

In explicit instruction practice, the teacher decided to select the texts from State University Entrance Test (UTBK) question as assigned instructional tasks based on Zimmerman \& Reed's (2020) recommendation that said the text should be intricate enough but still accessible for students to analyze it with Text Structure Strategy. This UTBK text is complex enough with some specific terminology but still accessible for students since it has 
short and simple sentences in every paragraph. The teacher also determined Meyer and Ray's (2011) suggestion regarding the enhancement of text complexity in the next practice. As a result, the first text that teacher used in modeling practice is a simple paragraph that use a single structure. Next in guided practice and independent practice, the complexity of the text has increased into combination of two structures, which are description and causation with five paragraphs.

The first instruction in text structure strategy is modeling activity. This activity was held on the first meeting. This activity is used to guide students in learning how to implement TSS in reading-task. Moreover, teacher will lead students' cognitive process to identify and analyze structural components in a text that can help authors to achieve their purpose (Zimmermann \& Reed, 2020). At first, the teacher demonstrated how to figure out text structure the writer uses by looking at signal words in the text. Then, the teacher demonstrated how to analyze paragraph structure to determine the topic sentence, supporting sentence, and concluding sentence in a text. The teacher would highlight every signal word in the text by using a yellow highlighter in Microsoft Word. Meanwhile, when analyzing paragraph structure, the teacher used blue to signify the topic sentence, green to signify the supporting sentence, orange to signify the example or further elaboration of supporting sentence, and red to signify the concluding sentence.

The current finding is also taking a similar pattern that Fisher and Frey (2015) had recommended in reading instruction modeling practice. They suggest students not meant to be passive learners in modeling practice, instead, they should also be thinking simultaneously and teacher should encourage them to express their thinking (Fisher \& Frey, 2015). As a result, the teacher decided to empower students to discuss and define topic sentences, supporting sentences, and concluding sentences in some paragraphs. This activity was proven could trigger students' activeness during modeling practice. Students were actively discussing paragraph structure with their friends, and conveying their analysis. At the end of the modeling practice activity, it was observed that students already grasp the main purpose of modeling and had ability to imitate teacher demonstration. Furthermore, this modeling practice absolutely can train students' cognitive skill before facing more complicated text in independent practice.

The scaffolding process also happened in guided practice. Guided practice is known as a collaborative practice between teacher and students as well as students and students. The teacher gave students guidance by helping them to analyze structural elements in a text (e.g. paragraph structure, and signal words), as well in translating some unfamiliar terms. Observation findings are in accordance with a discussion reported by Zimmerman and Reed (2020) that claimed re-teaching processes such as additional modeling, along with specific skills or concepts which students have difficulty, are also conducted throughout guided practice. The teacher moreover did re-modeling again since students still had difficulties in defining paragraph structure, especially supporting sentences. Moreover, the teacher also assisted students who were still unfamiliar with some new vocabulary in the text. These two kinds of scaffolding that teacher gave absolutely could help learners in reading and comprehending the text, as well as an addition in their schemata that can help them in the future reading. Furthermore, students also got some guidance from their friends during this collaborative practice. They actively discussed their analysis and helped each others to translate some unfamiliar words.

The teacher also guided students by asking them some guided questions during the practice. Students are assisted in paying attention to the function of the structural pattern of the text (Roehling et al., 2017) and shape their cognition toward related information in a text (Zimmermann \& Reed, 2020) through these guided questions. In this study, the teacher asked students some simple comprehension questions that can guide students when doing the 
practice. These comprehension questions are based on some simple text example in modeling practice, and also selected text-tasks in guided practice. Teacher also used these guided questions to seek out students' understanding toward text content. Students moreover could answer all of these questions correctly by only looking at the main ideas in the texts.

Table 2.

List of Guided Questions

\begin{tabular}{ll}
\hline Meeting & Guided Questions \\
1st Meeting & - What does the description text example talk about? \\
(Modeling & - What kind of sequence that the illustration shows? \\
practice) & - What does the sequential text example talk about? \\
& - What does comparison text example talk about? \\
& - What kind of comparison that the sentences talks about? \\
& - What are the similarities that author conveyed in the last sentence? \\
& - What does problem and solution text talk about? \\
2nd Meeting & - What does cause and effect text talk about? \\
(Guided practice) &
\end{tabular}

Besides guidance from human scaffolders, students were also gotten some assistance from text structure guide sheet. This guide sheet is used as the reference that students utilize while reading and analyzing structural components in selected text (Zimmermann \& Reed, 2020). The teacher had prepared a Text Structure Guide Sheet document by adapting Zimmerman and Reed's (2020) version. Moreover, the teacher version is in contrast in several parts with Zimmerman \& Reed's version. The teacher decided to remove guided questions columns and change them with structural hierarchical patterns or organization that writers used in the text. This change was used to remind students how the author arranged all ideas in a text. The teacher also adds an explanation of each structure in Indonesian language, so students can easily understand it.

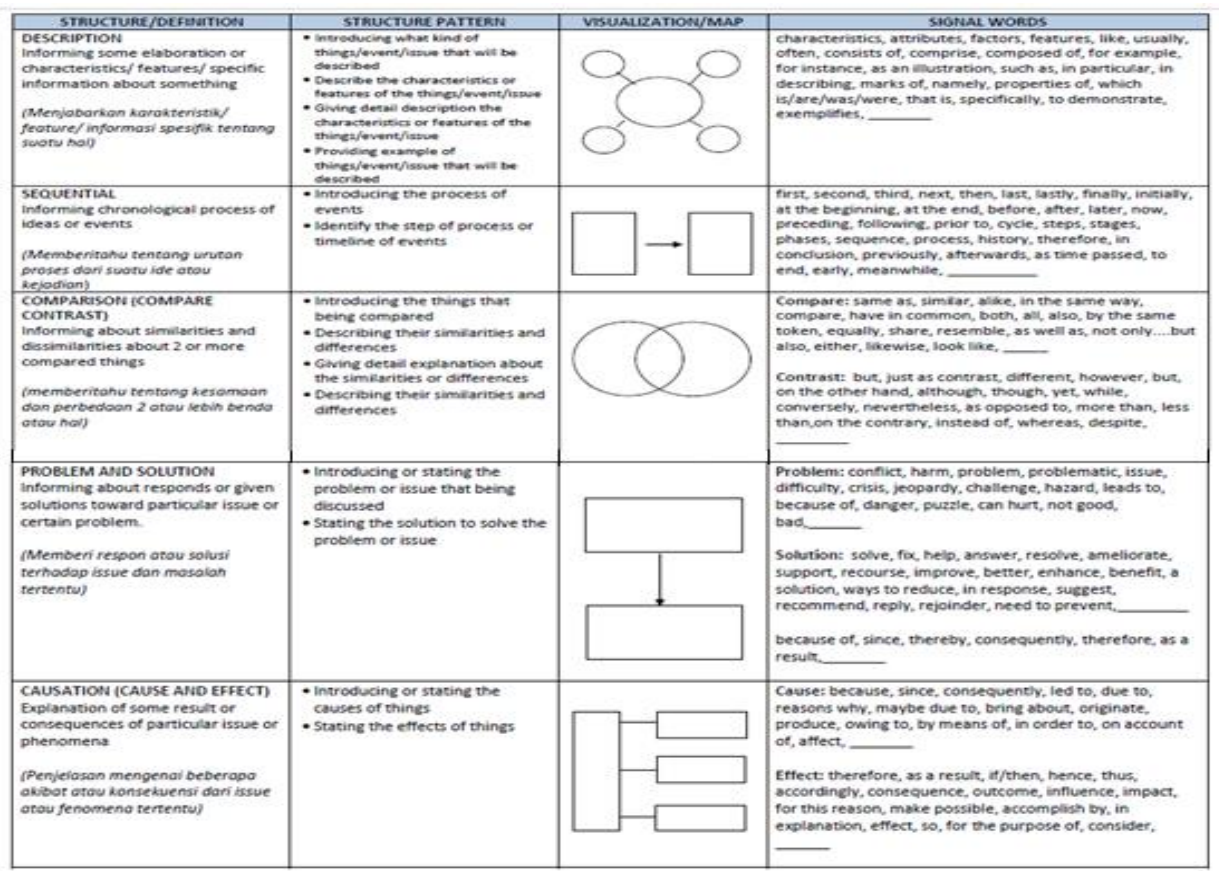

Figure 1

Text Structure Strategy Guide Sheet 
Last activity in explicit instruction is an independent practice that occurred on the last meeting. In independent practice, students analyzed and read a new selected text without assistance from teacher. This current study let students participate in a group to analyze the text. Teacher divided students into some groups that consist of five students. At first, teacher presented the new assigned text in the screen. The teacher asked all students to search some signal words. Teacher then would highlight those signal words by using a yellow highlighter in Microsoft Word. As a result, it was found that the text used causation structure. In this activity, it was observed that students are success in determining text structure by looking at signal words that writers used.

In the next step, the teacher asked the first group to determine the topic sentence and supporting sentence in the first paragraph. Students could easily determine the topic sentence but had difficulties and were uncertain when determining supporting sentences. Regarding that problem, the teacher asked another group to help them. Some students on another group helped them to translate some unfamiliar words and define supporting sentences.

When implementing the independent practice, the teacher faced some difficulties. Those difficulties have mainly emerged because of students' low participation and technical problems. The teacher observed that some students were still not actively engaged when analyzing the text independently. Students were uncertain and unconfident when doing this practice; hence, the teacher continually needed to trigger their activeness by calling each student in the group.

This independent activity also had limitations because of technical problems. Some students have abruptly left the meeting since they have a poor internet connection and phonetrouble. Furthermore, in order to solve those problems, the teacher decided not grouping students in some groups when analyzing the second paragraph. The teacher let all students to discuss their own opinions and analysis of each paragraph. After discussing their analysis, the teacher evaluated their performances. It was found that students were still struggling when defining supporting sentences since most of them were incorrect. Therefore, at the end of study, teachers gave them some feedback and guided them to re-analyze some paragraphs briefly.

However, this finding does not seem to take the same pattern with previous studies about independent practice (Hughes et al., 2017; Zimmermann \& Reed, 2020). While previous studies mostly recommend students individually analyze main important ideas in assigned reading tasks by making a summarization or graphic organizer, this current study preferred letting students express their analysis directly. Furthermore, this independent practice also could not be said as independent practice since students still get scaffolding from other students when defining supporting sentences.

Even though students still can understand the main ideas of each paragraph, students still have difficulties when defining supporting sentences independently. Researchers predict this problem because somehow, senior high school students, especially in Indonesia, still get no lesson about paragraph structure. This paragraph structure lesson is mostly taught at the university level. Thus, text structure strategy intervention is often used for English-speaking students and non-English-speaking students in higher levels, such as universities (Aghasafari, P.; Malayeri, 2015; Ghorbani Shemshadsara et al., 2019; Rohman, 2017; Wu \& Alrabah, 2020). Consequently, it is really necessary to give additional practice about paragraph structures to students to learn more in-depth about supporting sentences. Therefore, it can be concluded that independent practice in this current study was unsuccessfully occurred compared with other practices in previous meetings. 


\section{CONCLUSION}

This current study has the aim to describe the implementation of Text Structure Strategy instruction to scaffold 11th-grade students' at SMAN 1 Cibitung reading comprehension precisely in reading informational text. It can be concluded that text structure strategy instruction can scaffold students' reading comprehension through two main activities, namely introducing the basic concept of text structure strategy and teaching explicit instruction of text structure strategy activity. Furthermore, students got most scaffolding to comprehend an Informational text through explicit instruction, specifically on modeling and guiding practices. On the other hand, they still have difficulties when doing independent practice in this TSS instruction.

Therefore, this recent study suggests teachers to consider the amount of guiding practices when implementing this instruction. It is better to implement guiding practices in two or more meetings. This will make students experience a lot of practices as well as help them to understand about TSS more deeply. A teacher also should consider providing sufficient learning media to support students' independent practices, for instance, by using a learning management system. Regardless, future research could continue to explore the implementation of the graphic organizer and summarization tasks of text structure strategy instruction in online learning situations. In addition, students' perceptions and experiences of doing each explicit instruction in an online learning situation also might prove an important area for future research.

\section{REFERENCES}

Aghasafari, P.; Malayeri, F. A. (2015). Improving Students' Reading Comprehension Through Text Structure Tasks. International Journal of Educational Investigations, 2(3), 148-158. https://doi.org/10.24903/sj.v2i1.74

Andre, T. (1987). Processes in Reading Comprehension and the Teaching of Comprehension. Historical Foundations of Educational Psychology, 259-296. https://doi.org/10.1007/978-1-4899-3620-2_13

Bogaerds-Hazenberg, S. T. M., Evers-Vermeul, J., \& van den Bergh, H. (2020). A MetaAnalysis on the Effects of Text Structure Instruction on Reading Comprehension in the Upper Elementary Grades. Reading Research Quarterly, 1-28. https://doi.org/10.1002/rrq.311

Braun, V., \& Clarke, V. (2006). Qualitative Research in Psychology Using thematic analysis in psychology Using thematic analysis in psychology. Qualitative Research in Psychology, 3(2), 77-101. http://www.tandfonline.com/action/journalInformation?journalCode=uqrp20\%5Cnhttp:// www.tandfonline.com/action/journalInformation?journalCode=uqrp20

Creswell, J. W. (2013). John W. Creswell-Research Design_Qualitative, Quantitative, and Mixed Method Approaches-SAGE Publications (2013).pdf. SAGE.

Denton, C. A., Enos, M., York, M. J., Francis, D. J., Barnes, M. A., Kulesz, P. A., Fletcher, J. M., \& Carter, S. (2015). Text-processing differences in adolescent adequate and poor comprehenders reading accessible and challenging narrative and informational text. Reading Research Quarterly, 50(4), 393-416. https://doi.org/10.1002/rrq.105

Fisher, D., \& Frey, N. (2015). Teacher modeling using complex informational texts. Reading Teacher, 69(1), 63-69. https://doi.org/10.1002/trtr.1372

Ghorbani Shemshadsara, Z., Ahour, T., \& Hadidi Tamjid, N. (2019). Raising text structure awareness: A strategy of improving EFL undergraduate students' reading comprehension ability. Cogent Education, 6(1). https://doi.org/10.1080/2331186X.2019.1644704

Grabe, W., \& Stoller, F. L. (2020). Teaching Reading: Foundations and Practices. The Encyclopedia of Applied Linguistics, 2008, 1-9. 
https://doi.org/10.1002/9781405198431.wbeal1174.pub2

Harner, J. L. (2014). Reading and Learning from Informational Text. Cherry Lake.

Hughes, C. A., Morris, J. R., Therrien, W. J., \& Benson, S. K. (2017). Explicit Instruction: Historical and Contemporary Contexts. Learning Disabilities Research and Practice, 32(3), 140-148. https://doi.org/10.1111/ldrp.12142

Meyer, B. J. F., \& Ray, M. N. (2011). Structure strategy interventions: Increasing reading comprehension of expository text. International Electronic Journal of Elementary Education, 4(1), 127-152.

Ray, M. N., \& Meyer, B. J. F. (2011). Individual differences in children's knowledge of expository text structures: A review of literature. International Electronic Journal of Elementary Education, 4(1), 67-82.

Roehling, J. V., Hebert, M., Nelson, J. R., \& Bohaty, J. J. (2017). Text Structure Strategies for Improving Expository Reading Comprehension. Reading Teacher, 71(1), 71-82. https://doi.org/10.1002/trtr.1590

Rohman, A. (2017). Improving Students' Reading Comprehension Through Text Structure Tasks. Script Journal: Journal of Linguistic and English Teaching, 2(1), 1. https://doi.org/10.24903/sj.v2i1.74

Strong, J. Z. (2020). Investigating a Text Structure Intervention for Reading and Writing in Grades 4 and 5. Reading Research Quarterly, 55(4), 545-551. https://doi.org/10.1002/rrq.356

Tortorelli, L. S. (2019). Reading Rate in Informational Text: Norms and Implications for Theory and Practice in the Primary Grades. Reading Psychology, 40(3), 293-324. https://doi.org/10.1080/02702711.2019.1621011

Wijekumar, K., Meyer, B. J. F., Lei, P., Hernandez, A. C., \& August, D. L. (2018). Improving content area reading comprehension of Spanish speaking English learners in Grades 4 and 5 using web-based text structure instruction. Reading and Writing, 31(9), 19691996. https://doi.org/10.1007/s11145-017-9802-9

Wijekumar, K., Meyer, B. J., Lei, P., Beerwinkle, A. L., \& Joshi, M. (2020). Supplementing teacher knowledge using web-based Intelligent Tutoring System for the Text Structure Strategy to improve content area reading comprehension with fourth- and fifth-grade struggling readers. Dyslexia, 26(2), 120-136. https://doi.org/10.1002/dys.1634

Williams, J. P. (2005). Instruction in reading comprehension for primary-grade students: A focus on text structure. Journal of Special Education, 39(1), 6-18. https://doi.org/10.1177/00224669050390010201

Williams, J. P. (2018). Text structure instruction: the research is moving forward. Reading and Writing, 31(9), 1923-1935. https://doi.org/10.1007/s11145-018-9909-7

Wu, S. H., \& Alrabah, S. (2020). Harnessing text structure strategy for reading expository and medical texts among EFL college students. International Journal of Higher Education, 9(5), 36-45. https://doi.org/10.5430/ijhe.v9n5p36

Zimmermann, L. M., \& Reed, D. K. (2020). Improving Reading Comprehension of Informational Text: Text Structure Instruction for Students With or At Risk for Learning Disabilities. Teaching Exceptional Children, 52(4), 232-241. https://doi.org/10.1177/0040059919889358 